\title{
EPISTEMIC NORMS, THE FALSE BELIEF REQUIREMENT, AND LOVE ${ }^{1}$
}

J. Spencer ATKINS

\begin{abstract}
Many authors have argued that epistemic rationality sometimes comes into conflict with our relationships. Although Sarah Stroud and Simon Keller argue that friendships sometimes require bad epistemic agency, their proposals do not go far enough. I argue here for a more radical claim-romantic love sometimes requires we form beliefs that are false. Lovers stand in a special position with one another; they owe things to one another that they do not owe to others. Such demands hold for beliefs as well. Two facets of love ground what I call the false belief requirement, or the demand to form false beliefs when it is for the good of the beloved: the demand to love for the right reasons and the demand to refrain from doxastic wronging. Since truth is indispensable to epistemic rationality, the requirement to believe falsely, consequently, undermines truth norms. I demonstrate that, when the false belief requirement obtains, there is an irreconcilable conflict between love and truth norms of epistemic rationality: we must forsake one, at least at the time, for the other.
\end{abstract}

KEYWORDS: doxastic wronging, love, false belief requirement, epistemic partiality

\section{Introduction}

The epistemology of romantic love has been a largely neglected topic in the literature on epistemology and relationships. This literature has focused primarily on the epistemic demands of friendship (and the conflicts friendship poses to epistemology or deflating the conflict). ${ }^{2}$ Love, however, poses interesting epistemic demands excluded from friendship, and these demands show deeper conflict than friendship. Loving relationships make special demands on us; we owe things to our

\footnotetext{
${ }^{1}$ Thanks to Mattias Iser and Hilde Lindemann for helpful comments and suggestions on previous drafts.

${ }^{2}$ See Sarah Stroud, "Epistemic Partiality in Friendship" Ethics 116, 3 (2006): 498-524; Jason Kawall, "Friendship and Epistemic Norms," Philosophical Studies 165 (2013): 349-370; Allan Hazlett, A Luxury of the Understanding (Oxford: Oxford University Press, 2013); Katherine Hawley, "Partiality and Prejudice in Trusting," Synthese 191 (2014): 2029-2045; Christian Piller, "Evidentialism, Transparency, and Commitments," Philosophical Issues 20 (2016): 332-350; Lindsay Crawford, "Believing the Best: On Doxastic Partiality in Friendship," Synthese 196 (2019): 1557-1593; and Sanford Goldberg, "Against Epistemic Partiality in Friendship," Philosophical Studies 176 (2019): 2221-2242.
}

(C) LOGOS \& EPISTEME, XII, 3 (2021): 289-309 


\section{J. Spencer Atkins}

lovers that we do not owe to others. Some of these are demands are epistemic. It matters, for example, what we believe about our beloved, even when it is inconsistent with the evidence or even false. The demands of romantic love require that we sometimes become bad epistemic agents, or at least I will argue.

I argue here that Sarah Stroud's account of epistemic partiality is not radical enough. Stroud offers a constraint on epistemology: if epistemic rationality precludes elements of the good life, then we have reason to rework our definition of epistemic rationality in order to include elements of the good life. I argue, however, that love, an element of the good life, sometimes requires false belief and that a plausible account of rationality cannot ignore the need for true belief. Within the context of love, we may be required to hold false beliefs about our lover-this is the false belief requirement. I, therefore, propose that there are sometimes irreconcilable conflicts between epistemic norms and love. Love, in short, can require irrationality. Two facets of love can pose the false belief requirement: loving for the right reasons and the demand not to doxastically wrong.

I first briefly survey concepts from modern analytic epistemology, noting that they are inseparable from the truth condition. Knowledge, we will see, requires truth. I then turn to Stroud's epistemic partiality in friendship. In this section, I outline her account and then turn to the implications for epistemology and friendship. Next, I examine two facets of love, each of which may require bad epistemic behavior. I then argue that romantic love sometimes requires that we hold false beliefs. I first turn to Neil Delaney's account of loving for the right reasons. I argue for the agent-oriented claim that the loving agent must adopt the reasons the beloved holds dear about herself. The next section argues that lovers refrain from doxastic wronging. Lovers make themselves especially susceptible to doxastic wronging. Since true beliefs can doxastically wrong, lovers sometimes are required to believe falsely. In the last section, I explore one implication of the demand for false belief: that romantic love sometimes requires irrationality.

\section{The Unalterable Epistemic Norm of Truth}

I briefly want to consider the centrality of truth to modern analytic analyses of knowledge and epistemic rationality. An epistemically responsible agent, according to these views, must form beliefs that are true. ${ }^{3}$ I give examples and adaptations of

${ }^{3}$ This claim in controversial as there is a debate about whether truth is required for warranted belief. See, for example, Trenton Merricks, "Warrant Entails Truth," Philosophy and Phenomenological Research 55, 4 (1995): 841-855; Daniel Howard-Snyder, Frances HowardSnyder, and Neil Feit, "Infallibilism and Gettier's Legacy," Philosophy and Phenomenological Research 63, 2 (2003): 304-327; and E.J. Coffman, "Warrant without Truth?," Synthese 162 (2008): 
Epistemic Norms, the False Belief Requirement, and Love

the truth condition in modern analyses of knowledge and then suggest that truth is indispensable to modern analytic epistemology. If the truth condition is indispensable to epistemology, then the false belief requirement will be opposed to epistemic norms, namely believing truly. As I suggest later, when love poses the false belief requirement, love will be opposed to epistemic norms.

Consider, firstly, the "traditional" account of knowledge-knowledge as justified true belief or JTB analysis. This account has three conditions: $\mathrm{S}$ believes $\mathrm{p}$, $\mathrm{S}$ is justified in believing $\mathrm{P}$, and $\mathrm{p}$ is true. The remarkably non-controversial condition here is the truth condition. Post-Gettier analyses of knowledge have, as far as I can tell, maintained the truth condition.

Evidentialism is a supplemental account of knowledge that follows the JTB analysis. According to evidentialism, a belief counts as justified if and only if the available evidence supports the belief in question. W.K. Clifford writes: "It is wrong always, everywhere, and for anyone to believe anything upon insufficient evidence."” Evidence here is so important because the evidence tracks truth.

Consider now some conditions on knowledge. Sensitivity and safety are also deeply related to true belief. Robert Nozick proposes the sensitivity condition: $\mathrm{S}$ is sensitive to the truth if and only if $S$ would not hold a belief $p$ if $p$ were false. ${ }^{5}$ Responding to the many counterexamples to the sensitivity condition, Ernest Sosa proposes safety. The safety condition says that in any possible world where $\mathrm{S}$ holds a belief $\mathrm{p}, \mathrm{p}$ is true. That is, there is no possible world where $\mathrm{p}$ is false, and $\mathrm{S}$ believes p. ${ }^{6}$ Put simply, "S would not believe $\mathrm{p}$ without it being so that p."7 Safety and sensitivity, commonplace mechanisms in modern epistemology, are modal reconfigurations of the truth condition.

Consider the relevant alternatives condition on knowledge: $\mathrm{S}$ knows that $\mathrm{P}$ only if $\mathrm{S}$ can rule out relevant alternatives to $\mathrm{P} .{ }^{8}$ But not all alternatives are relevant-when, for example, someone, as I am trying to figure out where my wallet is, claims that aliens stole it. I need not rule this possibility out because this error

173-194.

${ }^{4}$ W.K. Clifford, "The Ethics of Belief," in The Ethics of Belief and Other Essays, ed. Tim Madigan (Amherst, MA: Prometheus), 77.

${ }^{5}$ Robert Nozick, Philosophical Explanations (Oxford: Oxford University Press, 1981).

${ }^{6}$ Ernest Sosa, "How Must Knowledge Be Modally Related to What Is Known?," Philosophical Topics 26 (1991): 373-384.

${ }^{7}$ Ibid., 378.

${ }^{8}$ I have taken this formulation of the necessary condition from Georgi Gardiner, "Risk and Relevance: How the Relevant Alternatives Framework Models the Epistemology of Risk," forthcoming in Synthese. See, as well, David Lewis, "Elusive Knowledge," Australasian Journal of Philosophy 74 (1996): 549-567. 


\section{J. Spencer Atkins}

possibility is "remote." What makes an alternative relevant or "non-remote"? Some argue that an error possibility is non-remote only if it in fact obtains. That is, whether or not a possibility is in fact true is what makes it relevant. ${ }^{9}$ This formulation, I think, largely tracks truth norms in epistemology-relevance is contingent upon what actually obtains.

These are but a few examples of the fundamentality of the truth condition in modern analyses of knowledge: knowledge "is a kind of relation to the truth."10 Analytic epistemology, I think we can reasonably conclude, cannot compromise the truth-it is indispensable to epistemology.

I argue later that love can sometimes pose the false belief requirement. Being a good lover sometimes requires we adopt false beliefs about our beloved. If this is right, then, given the fundamentality of truth to epistemic rationality, there is sometimes an irresolvable dilemma between epistemic rationality and love. This dilemma demonstrates a deeper epistemic conflict than Sarah Stroud's epistemic partiality, to which now I turn.

\section{Epistemic Partiality and Its Implication for Epistemology}

Sarah Stroud and Simon Keller have identified that there are sometimes conflicts between friendship and epistemology. ${ }^{11}$ Stroud says that friends owe one another epistemic partiality. I should not, for example, believe that my friend has done something that reflects poorly of his character; I owe it to him (in a manner that I do not owe to strangers) to interpret the evidence in the very best possible light. In short, friends owe one another differential epistemic practices. Such practices, however, do not go far enough; love requires something beyond epistemic partiality-false beliefs.

\footnotetext{
${ }^{9}$ See Lewis, "Elusive Knowledge."

${ }^{10}$ Jonathan Ichikawa and Matthias Steup, "The Analysis of Knowledge," in The Stanford Encyclopedia of Philosophy, ed. Edward Zalta, 2018.

${ }^{11}$ Stroud, "Epistemic Partiality;" and Simon Keller, "Friendship and Belief," Philosophical Papers 33, 3 (2004): 329-351. Others too acknowledge the tension between friendship and epistemology: William James, The Will to Believe and Other Essays in Popular Philosophy (New York: Dover Publications, 1896/1956): 1-31; and Scott Aikin, "Evidentialism and James' Argument from Friendship," Southwest Philosophy Review 24 (2008): 173-180. Some endorse a partialist position outside of the context of friendship: Jack Meiland, "What Ought We Believe? Or the Ethics of Belief Revisited," American Philosophical Quarterly 17 (1980): 15-24; Hazlett, A Luxury; and Piller, "Evidentialism, Transparency."
} 
Epistemic Norms, the False Belief Requirement, and Love

Stroud characterizes four epistemic demands of friendship. Following Sanford Goldberg, I use the following labels for the demands: Serious Scrutiny, Different Conclusions, Interpretive Charity, and Reason. ${ }^{12}$

First, Serious Scrutiny. We scrutinize negative claims about our friends: unsavory claims about our friends are harder to justify because we tend to be more skeptical when our friends are in question. If the evidence favors the unsavory claim, we "tend to devote more energy to minimizing the impact of unfavorable data than we otherwise would." 13

Stroud also thinks we derive Different Conclusions when our friends are in question: Friends "draw different conclusions and make different inferences than they otherwise would" with non-friends. ${ }^{14}$ Friends "are simply less likely to conclude that our friend acted disreputably, or that he is a bad person, than we would be in the case of a nonfriend."15

The third requirement is Interpretive Charity. We also interpret evidence against our friend more charitably than with non-friends-unsavory claims are just expressions of neutral, rather than malicious, character traits. Stroud thinks that partiality is "a matter of extending some interpretive charity to your friends than you naturally would to strangers." ${ }^{16}$ My friend's loud behavior, I may conclude, is not obnoxious, but rather "refreshingly forthright." 17

We, lastly, treat the fact someone is a friend as a Reason when we believe about them. Stroud writes: “The good friend's reason for adopting these differential epistemic practices seems to be simply that the person in question is her friend. But that someone is your friend is not a relevant epistemic reason...to form different beliefs about him than you would about anyone else." 18 These are the epistemic demands of friendship; Stroud thinks one must follow these demands to be a good friend.

Stroud notes that epistemic partiality-understood as the "unjustified departure from epistemic objectivity" - cuts against purist epistemological standards and norms, such as believing in accordance with the evidence. ${ }^{19}$ Friendship,

${ }^{12}$ Goldberg, "Against Epistemic Partiality,” 2224-2225.

${ }^{13}$ Stroud, "Epistemic Partiality," 505.

${ }^{14}$ Ibid., 506.

${ }^{15}$ Ibid.

16 Ibid., 507.

17 Ibid.

18 Ibid., 513.

${ }^{19}$ Ibid., 518. 


\section{J. Spencer Atkins}

therefore, opposes mainstream accounts of epistemic rationality. ${ }^{20}$ But how should we understand this tension?

Stroud gives three possible explanations for the tension between epistemic partiality in friendship and analytic epistemology. While she does not argue we should prefer any of them, I argue later that we should prefer what I call the radical response. First, friendship may simply require epistemic irrationality (or at least something that epistemic theories of rationality categorize as irrational). ${ }^{21}$ According to this response, friendship and epistemic rationality stand (or can stand) in irreconcilable conflict with one another, such that we must choose one over the other. If epistemic rationality precludes constitutive elements of the good life, e.g., friendship and, as I'll argue, romantic love, then so much the worse for epistemic rationality. We have reasons to prefer elements of the good life over epistemic standards of epistemology. Call this the radical response.

Next, Stroud suggests, following Henry Sidgwick, that friendship and rationality might be incommensurate values: "There is what you ought to believe from an epistemic point of view, what you ought to believe as a friend, but no adjudication of those competing claims which gives us what you ought to believe simpliciter."22 According to this suggestion, when epistemic rationality and friendship demand different beliefs, there is no reason to prefer one to the other. Call this the incommensurate response.

Lastly, Stroud suggests that the requirements of the good life are a constraint on epistemology, similar to the constraint of ethical theories. Michael Stocker notes that because "modern ethical theories" exclude relationships that are necessary for the good life we have reason to reject such moral theories. ${ }^{23}$ Stroud proposes that a

\footnotetext{
${ }^{20}$ Needless to say, Stroud's view has attracted much dissent. Many reject the proposed conflict between the norms of friendship and epistemic norms. Jason Kawall ("Friendship and Epistemic Norms") and, to some extent, Katherine Hawley ("Partiality and Prejudice") argue that the epistemic demands of friendship fall within the bounds of epistemic propriety because friendship's demands are not as strenuous as Stroud supposes. Lindsay Crawford ("Believing the Best") argues that evidentialist responses to epistemic partiality fail. The attitudes constitutive of friendship, she argues, preclude partiality. Friendship cannot generate reasons in the way Stroud argues. Sanford Goldberg argues that value-reflecting reasons make the demands of friendship and epistemic partiality "epistemically innocuous" ("Against," 2225). Value-reflecting reasons are reasons generated from what we value, which is consistent with our total available evidence. I bracket these objections. My goal here is to further this dissent but in the other direction: I argue there is more conflict between epistemic norms and the norms of the good life than Stroud appreciates.

${ }^{21}$ Stroud, "Epistemic Partiality," 520.

22 Stroud, "Epistemic Partiality," 519.

${ }^{23}$ Michael Stocker, "The Schizophrenia of Modern Moral Theories," The Journal of Philosophy 73, 14 (1973): 453-466.
} 
Epistemic Norms, the False Belief Requirement, and Love similar constraint obtains for epistemology: "If standard epistemological theories condemn as irrational something that is indispensable for the good life-so that we have compelling reason not to comply with the demands of those theories-then perhaps we should question whether those theories offer an adequate account of epistemic rationality after all." ${ }^{24}$ Call this the constraint response.

Consider now the limits of Stroud's view: friendship and epistemic partiality does not require we form false beliefs. She writes: "What seems to be characteristic of the good friend is not a stubborn denial of obvious incontrovertible facts about [one's] friend but something more subtle." ${ }^{25} \mathrm{I}$ argue in the next sections that this is not right; differential epistemic practices may sometimes require forming false beliefs. We might be required to believe falsely in order to love romantic partners for the right reasons or to avoid a doxastic wronging. If this is the case, then romantic relationships sometimes pose epistemic demands that Stroud neglects. I argue, moreover, that if there is a demand for false belief, then we should reject Stroud's constraint response: the epistemic costs—-doing away with the truth condition-are too great for any plausible epistemology. Love, in short, requires irrationality: we need, at least, conceptual space for this possibility. I argue that the radical response best affords this space. For now, I turn to the demand to believe falsely within the context of romantic relationships.

\section{Love Requires False Beliefs... Sometimes}

While romantic relationships may demand epistemic partiality-which does not necessarily entail a demand to believe falsely-I argue that romantic love sometimes poses the further demand to believe falsely. Let's call this the false belief requirement. The false belief requirement violates a more fundamental epistemic norm than Stroud's epistemic partiality: the truth condition. We will see how this poses a problem for reconciling norms of the good life and purist epistemology. To substantiate the false belief requirement, I turn to Neil Delaney. ${ }^{26}$ I first show that love demands loving for the right reasons; I then argue that this demand sometimes poses the false belief requirement.

Delaney argues that lovers desire to be loved for the right reasons. The right reasons are the properties that the person takes to be central to her identity. Delaney writes: "A person A wants a romantic partner B to love him for properties that A takes to be central to his self-conception. Not necessarily all of the properties,

\footnotetext{
${ }^{24}$ Stroud, "Epistemic Partiality," 522.

${ }^{25}$ Ibid., 506.

26 Neil Delaney, "Romantic Love and Loving Commitment: Articulating a Modern Ideal," American Philosophical Quarterly 33 (1996): 339-356.
} 


\section{J. Spencer Atkins}

perhaps not even just any plurality; but definitely some."27 If I, for example, deeply identity as a philosopher, my partner must appreciate that part of my identity. Delaney thinks my partner does not have to know about philosophy, but rather she must appreciate that I love philosophy and identify as a philosopher. The idea here is that "people generally want those things about themselves that they take to be at the core of their identity to figure as grounds in the attitude their lover takes toward them. ${ }^{28}$ Lovers desire to be seen for what they value about themselves.

Delaney points out that we desire to be loved for the right reasons, even when we have a largely inaccurate conception of ourselves. Consider, for instance, the "goodhearted teenage rebel" with a "decent, gentle soul" who sees himself as a "nihilistic desperado." ${ }^{29}$ This boy's dramatic conception of himself is not accurate; he does not want to see himself as he really is, which is kind and gentle. This person, according to Delaney, "wants to be loved for what he takes to be central to his selfconception." ${ }^{30}$ Lovers desire to be loved for the features they take to be important to their identity, even if that involves a false conception of who they are.

I argue that the lover needs to love the features central to her beloved's selfconception, even if those features are false. Delaney gives a recipient-oriented account of loving for the right reasons, as opposed to an agent-oriented account. Delaney's account does not necessarily imply that the lover must love the beloved for the right reasons, merely that the beloved desires that she be loved for these reasons. If the lover is not obligated to love for the right reasons, then the lover can ignore the beloved's desire to be loved for the right reasons. In order for my argument to work, I need the agent-oriented claim that lovers are obliged to love for the right reasons.

In response, it is in the lover's interest to love the beloved for the right reasons. The reason is that the lover also wants to be loved for the right reasons too. There seems to be a reciprocal nature of loving for the right reasons. If the lover knows that he wants to be loved for the right reasons, it seems clear that he ought to also love his beloved for the right reasons.

Loving for the right reasons, moreover, is beneficial to the lover. Love involves benefitting one's lover by letting her be seen as she desires to be seen. Many argue that a desire to benefit one's beloved is partly constitutive of love. ${ }^{31}$ Benefit

\footnotetext{
27 Ibid., 343.

${ }^{28}$ Ibid.

${ }^{29}$ Ibid.

${ }^{30}$ Ibid., 344.

${ }^{31}$ See, for instance, Henry Sidgwick, The Methods of Ethics (Indianapolis: Hackett, 1874/1981);

Gabriele Taylor, "Love," Proceedings of the Aristotelian Society 76, 1 (1976): 147-164; Laurence
} 
Epistemic Norms, the False Belief Requirement, and Love

here involves bringing about the lover's good within reason. If the lover desires to be psychologically seen for certain things, I think love demands we see her for the things she loves about herself. Love, in short, demands loving for the right reasons.

If there is a demand to love for the right reasons and the right reasons are sometimes false, then love sometime poses the false belief requirement. The idea here is that to love in the way that the beloved desires, to give him what he needs, we must adopt some false beliefs about who he is or what he has done. Thus, the demand to love for the right reasons sometimes poses the false belief requirement. Given the false belief requirement, I argue that we should prefer Stroud's radical response.

Now, there may be some limitation to the false belief requirement. Not every false self-conception needs to be loved-"No honey, you're not the greatest criminal mastermind of the twenty-first century"- especially given that Delaney thinks we need not love every identity-constitutive feature of our beloved. But surely there are some instances where love makes the false belief requirement. One plausible criterion is that the lover will not obtain psychological fulfillment without being loved for that reason: "[I]f in fact there is a significant disparity, from the point of view of psychological fulfillment they want to think of their lover as valuing them for the same sorts of reasons that they themselves do." 32 Another plausible set of cases where love may require false belief are cases of striving, where we prematurely see ourselves as what we desire to become. Such cases may require taking on dubious epistemic practices. I say more about striving cases momentarily, but I first turn to a couple of objections.

Consider another problem. Delaney suspects that discrepancy between the lover's self-conception and who she actually is reveals a defective love. He writes: "I suspect that in cases of radical disparity between who you take yourself to be and who you are fulfilling romantic relationships are effectively precluded." 33 The idea here is that one cannot have fulfilling romantic love and self-discrepancy: it will be in some way deficient. If this kind of love is defective, then the tension between rationality and love is in some sense expected because the love is bad to begin with.

Thomas, "Reasons for Loving," in The Philosophy of (Erotic) Love, eds. Robert Solomon and Kathleen Higgins (Lawrence: University of Kansas Press, 1991), 467-476; Harry Frankfurt, "Some Thoughts about Caring," Ethical Perspectives 5 (1998): 3-14; Robert Nozick, The Examined Life (New York: Simon \& Schuster, 1989); and John Rawls, A Theory of Justice (Cambridge, Mass: Harvard University Press, 1971).

32 Delaney, "Loving Commitment," 344.

${ }^{33}$ Ibid., 354, ff 18. 


\section{J. Spencer Atkins}

If the love were not defective, then there would be no conflict. Thus, discrepancy between love and epistemic rationality only happens in cases of bad love. ${ }^{34}$

To demonstrate the veridical nature of love, Delaney cites Nathaniel Branden. ${ }^{35}$ Branden argues that psychological visibility is central to romantic love. Companionship is pleasurable and consequently valuable because it affords the opportunity to feel "seen" by another. ${ }^{36}$ We can only, according to Braden, view ourselves conceptually-we know things about ourselves—but we need others to view ourselves perceptually, "as concrete objects 'out there." 37 Other consciousnesses function like a mirror. Being seen in this way is recognition of personhood. The feeling of being seen is psychological visibility. Romantic love affords a "uniquely powerful" experience of visibility because lovers share a fascination with one another unlike any other relationship. ${ }^{38}$

Psychological visibility requires a veridical self-conception. Branden writes: "If [the other's] view of us is consonant with our deepest vision of who we are (which may be different from whom we profess to be), and if [the other's] view is transmitted by their behavior, we feel perceived, we feel psychologically visible." ${ }^{39}$ This conditional seems to assume that we have a largely accurate sense of who we are. To be seen, we must see ourselves as we are.

Branden's account of psychological visibility, as I noted above, spells trouble for my argument. The discrepancy between who we think we are and who we actually are precludes us from becoming psychologically visible.

But I do not think that psychological visibility needs to be totally veridical. Consider cases of striving toward ends. Many of us have experienced the need to change for the better. Whether that be the ambition of accomplishing more than others expect us to or looking at ourselves in the mirror after making a grave mistake, we often desire change. The desire for change sometimes comes with a radical, and often enough premature, change in how we perceive ourselves-I am a good person, or I am a great philosopher. Even if those things are not strictly speaking true at the time, it seems to me that loving for the right reasons means that our lover will see us as what we strive to be.

\footnotetext{
34 Thanks to Cullin Brown for bringing this objection to my attention.

${ }^{35}$ Nathaniel Branden, "Love and Psychological Visibility," in Friendship, ed. Neera Kapur Badhwar (Ithaca: Cornell University Press, 1993), 65-72.

${ }^{36}$ Ibid, 67.

37 Ibid., 69.

${ }^{38}$ Ibid.

${ }^{39}$ Ibid., 70.
} 
Epistemic Norms, the False Belief Requirement, and Love

Sarah Paul and Jennifer Morton argue that whether or not we "believe in others" when they strive toward goals will depend on the relationship we hold with the other person. ${ }^{40}$ If this is right, then we ought, it seems, to believe in our lovers when they attempt to accomplish their goals, even if believing that is inconsistent with the evidence. They argue that doubting whether our significant others can achieve their goals can wrong them, in the absence of "significant and specific evidence that this is so." 41 To a certain degree, we must believe in spite of the available evidence to believe our lovers will accomplish their goals. Failing to do so amounts to a wronging. I am arguing here that the goal we strive toward often functions as a reason we desire to be loved for. We want to be seen and valued as a great philosopher, for example, even if that is an end we have yet to achieve.

Part of being psychologically visible, I have argued, sometimes involves being seen as something we are not. That is, psychological visibility does not always strictly speaking require truth. Truth is not required, for example, in striving cases where we desire to premature be seen as what we hope to become. Thus, psychological visibility is not wholly veridical, as Branden and Delaney argue. If Delaney's account of loving for the right reasons is agent-oriented, as opposed to merely recipientoriented, then the false belief requirement may follow, for example, in striving cases.

Consider yet another problem with my account of Delaney's view: it assumes that we can make ourselves believe a proposition. This view is doxastic voluntarism. What I have said supports the following kind of scenario. Albert and Beth are lovers. Albert tells Beth that he is taking up dancing lessons. He is a dancer. Beth, who has seen Albert's two left feet in action, knows Albert is a crummy dancer; she also reasonably foresees that Albert will abandon his interest in dancing. She also knows, however, that it is important for Albert to be seen as a dancer, so she makes herself believe that Albert is a dancer, rather than a flippant and temporary danceenthusiast. That is, she in some way makes herself believe that Albert is a dancer, even though this conclusion is likely false and is formed in spite of the evidence.

Belief formation, according to doxastic voluntarism, is more like doing jumping jacks than a kneejerk reflex. That is, we can come to believe something and stop believing the very same thing at will. This view is scrutinized: many argue that beliefs are at the mercy of evidence. According to these views, we cannot turn beliefs on and off; there is no deliberation about whether to believe whether it is raining or not; we simply come to believe things independently of our control. ${ }^{42}$ In response,

${ }^{40}$ Sarah Paul and Jennifer Morton, "Believing in Others," Philosophical Topics 46 (2018): 75-96

${ }^{41}$ Ibid., 94.

${ }^{42}$ See, for example, Bernard Williams, "Deciding to Believe," in Language, Belief, and Metaphysics, eds. Howard Kiefer and Milton Munitz (Albany: SUNY Press, 1970), 95-111; William Alston, "The 


\section{J. Spencer Atkins}

there are a growing number of defenders of doxastic voluntarism. ${ }^{43}$ I do not have time to contribute to the discussion on doxastic voluntarism, but I rely on the authors cited to demonstrate doxastic voluntarism is plausible. I turn now to a separate but related question.

We might wonder how we can willingly form a false belief. It is a common idea that beliefs track truth, and so we cannot make ourselves believe something false. How is it that I can be required to form a false belief when it is impossible to do so? In response, I return to doxastic voluntarism. As I said, voluntarism says that we have some degree of control over our beliefs. Nishi Shah argues that we have the ability to select different bodies of evidence and slowly influence our beliefs to conform with those various evidence bodies. ${ }^{44}$ Matthias Steup argues that our beliefs respond to epistemic reasons, which are to some degree under our control. ${ }^{45}$ However it is that we can voluntarily change our beliefs, the false belief requirement will demand it. The false belief requirement might sometimes demand we examine different bodies of evidence or it might demand we change our belief quickly. For now, I return to my discussion of Delaney.

Delaney's claim about loving for the right reasons has an implication for our epistemic norms. I have argued that loving for the right reasons sometimes poses the false belief requirement. That is, we must believe certain things about another person that are false. This clearly cuts against epistemic norm of believing truly. Nevertheless, if Delaney is right, then a plausible epistemic demand of romantic relationships is to form beliefs about our beloved's identity, even when those beliefs are not true. Delaney's account can pose the false belief requirement.

Note that this conclusion deviates significantly from Stroud's epistemic partiality. As I've been at pains to show, relationships require more radical deviations

Deontological Conception of Epistemic Justification," Philosophical Perspectives 2 (1988): 257299; and Andrei Buckareff, "Acceptance and Deciding to Believe," Journal of Philosophical Research 29 (2004): 173-190.

43 See Carl Ginet, "Deciding to Believe," in Knowledge, Truth and Duty, ed. Matthias Steup (Oxford: Oxford University Press, 2001), 63-76; Robert Audi, "Doxastic Voluntarism and the Ethics of Belief," in Knowledge, Truth and Duty, ed. Matthias Steup (Oxford: Oxford University Press, 2001), 93-111; Nishi Shah, "Clearing Space for Doxastic Voluntarism," The Monist 85 (2002): 436-445; Matthias Steup, "Belief Control and Intentionality," Synthese 188 (2012): 145-163; Amy Flowerree, "Agency of Belief and Intention," Synthese 194 (2016): 2763-2784; Rima Basu, "Can Beliefs Wrong?," Philosophical Topics 46 (2018): 1-17; and Rima Basu and Mark Schroeder, "Doxastic Wronging," in Pragmatic Encroachment in Epistemology, eds. Brian Kim and Matthew McGrath (New York: Routledge, 2018), 181-205.

${ }^{44}$ Shah, "Clearing Space," 436-445.

45 Steup, "Belief Control," 145-163. 
Epistemic Norms, the False Belief Requirement, and Love

from epistemic norms than Stroud's account shows. Recall that her account of epistemic partiality excludes the false belief requirement. Loving for the right reasons points to a much more radical epistemic tension than Stroud's epistemic partiality. None of the mechanisms of epistemic partiality require that we believe falsely about our friend: we may merely require more evidence or interpret character claims charitably. The epistemic requirements of love involve worse epistemic behavior because love can sometimes demand we hold a false belief about our lover. This feature of romantic love, i.e., the more radical epistemic responsibility we hold to our lover, gives us reason to think that romance sometimes just requires irrationality, or behaviors that analytic epistemology would categorize as irrational.

To further my argument, I turn now to another facet of loving relationships: the demand not to wrong one another. Specifically, I examine doxastic wronging in the context of loving relations. Since true beliefs can sometimes wrong, lovers may need adopt false beliefs in order to avoid doxastically wronging one another. This facet of love, I conclude, can pose the false belief requirement.

\section{Doxastic Wronging and Romantic Love}

Doxastic wronging reveals the demand to believe falsely within the context of romantic relationships. This section has three movements. I first argue that romantic partners are especially susceptible to doxastic wronging. Given the intimacy and vulnerability required for romantic relations, lovers stand in a very special position with one another-one in which they are especially prone to doxastic wronging. Second, following Rima Basu, ${ }^{46}$ I argue that true beliefs can also wrong. True beliefs that wrong, I argue lastly, reveal a demand for lovers to sometimes believe in spite of the available evidence or even falsely. Lovers hold special responsibilities not to doxastically wrong one another, even with true beliefs. Love's demand not to doxastically wrong one's lover can sometimes pose the false belief requirement.

According to Rima Basu and Mark Schroeder, the content of some beliefs can constitute a moral wronging. ${ }^{47}$ It is not the manner in which the belief was formed, e.g., whether the belief was formed on the basis of some morally problematic bias or faulty evidence, nor is it the actions and dispositions that follow from the belief. Doxastic wrongings occur at beliefs themselves, not "upstream" or "downstream" from the belief.

\footnotetext{
${ }^{46}$ Rima Basu, "What We Epistemically Owe to Each Other," Philosophical Studies 176 (2019): 915931.

47 Basu and Schroeder, "Doxastic Wronging," Basu, "What We Owe;" Mark Schroeder, "When Beliefs Wrong," Philosophical Topics 46 (2018): 115-127.
} 


\section{J. Spencer Atkins}

Basu and Schroeder identify three conditions of a doxastic wronging, which I call the directed condition, the belief itself condition, and the content condition. ${ }^{48}$ The directed condition says that a belief wrongs a particular person; it is not just wrong in general. The belief itself condition is that holding the belief-as opposed to how the belief was formed or the actions and dispositions that follow from the belief-is what wrongs. And, lastly, the content condition is that the content of the belief wrongs. Doxastic wrongings obtain in virtue of what is believed.

To illustrate doxastic wronging within the context of love relations, I turn to a touchstone case that supports doxastic wronging:

Wounded By Belief. Suppose that Mark has an alcohol problem and has been sober for eight months. Tonight, there's a departmental colloquium for a visiting speaker, and throughout the reception, he withstands the temptation to have a drink. But, when he gets home his partner, Maria, smells the wine that the speaker spilled on his sleeve, and Mark can tell from the way Maria looks at him that she thinks he's fallen off the wagon. Although the evidence suggests that Mark has fallen off the wagon, would it be unreasonable for Mark to seek an apology for what Maria believes of him? ${ }^{49}$

Something is the matter with Maria's belief. It fails to appreciate Mark's determination to resist drinking; what is an accomplishment to Mark is a sign of defeat for Maria. Basu and Schroeder conclude that Maria has wronged Mark with the content of her belief. ${ }^{50}$

Does it matter that Maria is Mark's partner? I believe so. If Maria were a stranger on a train, for instance, it doesn't seem to matter quite as much that she believes that Mark drank..$^{51}$ Mark and Maria, we might assume, have been working

\footnotetext{
48 Basu and Schroeder, "Doxastic Wronging," 181-205.

49 Basu, "What We Owe," 917.

${ }^{50}$ Here one might wonder whether if it is the belief itself that wrongs or Maria's expression that follows from the belief. Consider another case from Basu ("What We Owe") to invoke the belief contents can wrong: Racist Hermit. "One day a racist hermit finds a newspaper highlighting the academic success of Sanjeev. The hermit concludes that Sanjeev smells of curry. Suppose that Sanjeev has recently made curry-rendering the hermit's belief true." There's no risk of the hermit meeting Sanjeev, nor contributing to any racist structures, yet his belief still seems wrong. One explanation is that the hermit wrongs Sanjeev with the content of his belief.

${ }^{51}$ What's the difference between the racist hermit's belief and the stranger's belief? One is a doxastic wronging, while the other is not. The racist hermit's belief is a doxastic wronging because it is based on a generalization. The stranger's belief that Mark has had a drink does not appeal to a generalization. Rather, her belief is specific to Mark, yet the stranger does not know that Mark has struggled for sobriety. In order to doxastically wrong Mark, I think one must know about his alcoholism. She does not understand the significance of her belief.
} 
Epistemic Norms, the False Belief Requirement, and Love

on Mark's drinking for a long time. Maria understands how hard Mark has worked and, therefore, should view the night as a success. If Maria is a stranger, she will not know to view the dinner party as a success for Mark's drinking. If Maria infringes on an epistemic duty to Mark in virtue of being Mark's lover, then it seems that lovers must believe rightly about one another even when the evidence suggests otherwise-lovers, that is, possess epistemic duties because they are lovers.

Lovers stand in a privileged position with one another-they know things not usually shared with other people. This special position makes us especially vulnerable to doxastic wronging. Perhaps Mark's colleagues do not know he is a recovering alcoholic. Maria, perhaps, is the only one who can wrong him in this way. She is, perhaps, the only one with the responsibility to trust him about his recovery.

We might imagine that Mark trusts Maria more than other people. Given the proximity of their relation, it matters to Mark what Maria thinks about him, and vice versa. I think that Mark's potential expectation for Maria to believe well of him makes him especially vulnerable to doxastic wronging. In many cases, we would not care what a stranger believes of us, where we would care what our lover believes of us.

As lovers, we stand in a special position to doxastically wrong. We know more about our lovers than anyone else, so we can more easily wrong them with our beliefs. Though strangers can doxastically wrong one another-like racist beliefslovers have made themselves vulnerable to one another; lovers know one another's weaknesses, just like Maria knows Mark's secret alcoholism. It follows that her believing Mark drank is a doxastic wronging, whereas if a stranger formed such a belief, no apology would be necessary. This is because the stranger does not have the larger context of Mark's alcohol recovery.

So far, I have argued that lovers stand in an especially vulnerable position with one another with regard to doxastic wronging. I now turn to the question of whether beliefs must be false to wrong. There is nothing about a belief's being true that precludes it from wronging-even true beliefs, therefore, can doxastically wrong others. ${ }^{52}$ Given that true beliefs can wrong, it follows that sometimes we should form

52 I follow Basu ("What We Owe") in making this point. It is, however, controversial. Mark Schroeder ("When Beliefs Wrong") argues that doxastic wrongings only occur when the belief in question is false. This poses some issue with my argument that true beliefs can doxastically wrong. He distinguishes between subjective and objective wrongings. For example, suppose Richard is behind one of three closet doors and Gretchen fires a gun at one of these doors, missing Richard. We would be inclined to say that Gretchen's action is both objectively and subjectively wrong: objectively wrong because she poses a needless risk on Richard and subjectively wrong because she did not have sufficient evidence to believe that Richard was not behind the door she shot. 


\section{J. Spencer Atkins}

false beliefs about other people. Given that doxastic wronging does not occur in virtue of problematic belief formation processes, beliefs can wrong even if they are formed consistently with the available evidence. Thus, beliefs can wrong even when they are the product of reasonable epistemic processes and are true: none of the essential conditions of doxastic wronging precludes this possibility.

Basu argues that even true beliefs can wrong..$^{53}$ Included in this responsibility, therefore, is the demand to refrain from holding some true beliefs. I argue, momentarily, that lovers may sometimes be required to refrain from forming true belief and may be required to adopt false beliefs. But first, consider a case meant to show true beliefs can wrong:

Racist Hermit. Suppose a racist hermit in the woods discovers trash containing an alumni newsletter from Sanjeev's university, which includes Sanjeev's photo. The hermit immediately concludes that the pictured person-Sanjeev-smells of curry. Suppose also that Sanjeev happens to have recently made curry, so in this instance the hermit's belief is true-Sanjeev does smell of curry. Has the hermit wronged Sanjeev? ${ }^{54}$

Here is a proposed example of a belief that is true but nevertheless wrongs another person. The hermit, in order to avoid the wronging, must either withhold belief or believe falsely. If asked, the hermit ought to respond that Sanjeev does not smell of curry or that he has withheld belief. But the way we form beliefs is often automatic; beliefs simply appear. If the hermit can't help forming a belief in this case, then it seems that he must form the false belief that Sanjeev does not smell of curry. That is, the hermit is obligated, in order to avoid the doxastic wronging, to form a belief that is false, namely that Sanjeev does not smell of curry. ${ }^{55}$

Objective and subjective wrongings can however come apart. Beliefs too can objectively and subjectively wrong, and they can come apart for beliefs too. For example, according to Schroeder, if a belief would wrong another person, that counts as a reason not to adopt that belief. Suppose that a belief is true, and someone adopts it without having further evidence. That person would have subjectively wronged whoever he believes about, but he would not have objectively wronged him since the belief is true. He subjectively wrongs him because of lack of evidence. If Schroeder is right, then my claim that true beliefs can wrong is not right; however, true beliefs, even though they cannot objectively wrong, can subjectively wrong on this account. Thus, it might be that lovers must refrain from believing when their beliefs would subjectively wrong-and, it is possible, the false belief requirement may still stand. For now, I continue operating under the assumption that true beliefs can wrong.

53 Basu, "What We Owe," 915-931.

${ }^{54}$ Ibid., 919.

55 There is again the question of whether doxastic voluntarism is true. I point to the authors cited above for a defense of voluntarism. 
Epistemic Norms, the False Belief Requirement, and Love

But we might wonder what the wronging is here. Perhaps the wronging here is not the belief that Sanjeev smells of curry, rather the wronging is believing that Sanjeev and others of his ethnic group are inferior because they smell of curry. The hermit can believe that Sanjeev smells of curry without also believing that Sanjeev and members of his ethnic group are inferior and vice versa. If this is right, then this is not an example of a true belief that wrongs, since the true belief is does not by itself wrong. The inference, rather, to the false belief that Sanjeev and members of his ethnic group are inferior is the wronging.

In response, Basu finds it intuitive that the belief that Sanjeev smells of curry is a wronging. She thinks that there is some harm involves in the hermit's belief: "the harm is a relational harm: the hermit fails to relate as he ought." 56 This seems right, but there is more to be said here. Believing on the basis of stereotypes, I think, is the relational failure here. The reason is that stereotypes fail to appreciate an individual as distinct from her reference class. ${ }^{57}$ The hermit does not consider the possibility that Sanjeev has distinct features from his reference class: perhaps he does not smell of curry because he does not like curry. To relate to Sanjeev in the right way, the hermit must consider him as an individual. Failing to see Sanjeev as an individual is what makes the hermit's belief wrong. Thus, the hermit's true belief still seems to wrong Sanjeev.

That true beliefs can wrong is an important claim for my argument. If true belief can wrong, then we must either withhold belief or believe falsely, else we commit a wrongdoing. Lovers, who as I have argued have special obligation not to doxastically wrong, will sometimes have to either refrain from believing or believe falsely.

Suppose for example that Maria's belief that Mark has had alcohol is true. Even if that belief is true, Maria's belief may still wrong Mark. Maria fails to take seriously the possibility that the wine was there by accident, even if Mark did drink. I suggest that the demand not to doxastically wrong sometimes requires believing falsely. Perhaps Maria, for example, should still believe that Mark had not had anything to drink, even when the belief is true. If Maria has to form a belief, then it seems like, given her proximity to Mark, she ought to default to the belief that he has resisted alcohol. Perhaps Maria's belief constitutes a wronging until Mark comes clean about his drinking.

\footnotetext{
56 Basu, "What We Owe," 919. Basu’s emphasis.

${ }^{57}$ For more about the moral wrongings that stem from failing to distinguish individuals from their reference class, see J. Spencer Atkins, "Moral Encroachment, Wokeness, and the Epistemology of Holding," forthcoming in Episteme.
} 


\section{J. Spencer Atkins}

Now I argue that lovers possess a special obligation not to wrong one another. I think that the demand not to doxastically wrong our lover comes from a common feature of love: the desire to benefit or bring about the good of the beloved. Many authors identify love as a two-pronged desire: the desire for union with the beloved and the desire for the lover's good. ${ }^{58}$ To wrong another with one's beliefs is largely inconsistent with the desire to bring about the good of the beloved. We might also think, moreover, that doxastic wronging inhibits union with the beloved, as wronging another person often drives her away. The desires of love-to benefit and share union with - seem to point to the demand, even the self-imposed demand, to refrain from doxastic wronging. It, at the very least, points to the conclusion that to act consistently with love, one would refrain from doxastic wrongings.

Love, given the intimacy and vulnerability of the romantic relation, must demand lovers not wrong one another, including with belief. The plausibility of doxastic wronging, therefore, points to the conclusion that love can sometimes pose the false belief requirement, at least until there is more available evidence. I now draw out an implication of this conclusion: that the best explanation for the false belief requirement is the radical response-that love and epistemic rationality, specifically believing truly, are sometimes mutually exclusive.

\section{In Favor of the Radical Response}

Recall that Stroud gives three possible interpretations of the relationship between for partiality and epistemic norms: radical response, incommensurate response, and constraint response. She thinks that each of these responses can account for the relation between partiality and epistemic norms. I argue now that the radical response is the best explanation of epistemic norms and love's demand to believe falsely sometimes. The false belief requirement poses too strong of a constraint on purist epistemology. That is, adjusting purist epistemology to meet love's demand to sometimes believe falsely jeopardizes a foundational assumption of epistemology, to believe truly. Love and epistemic rationality stand opposed to one another.

The constraint response can reasonably explain Stroud's epistemic partiality in friendship but not the false belief requirement. According to this response, the demand for epistemic partiality in friendship requires that we take epistemic

\footnotetext{
58 J. David Velleman ("Love as a Moral Emotion," Ethics 109 (1999): 338-374) identifies this view of love as the predominant view among analytic philosophers. Given the wide acceptance of this view of love, I limit my discussion to this view. Authors that hold some version of this view are Henry Sidgwick (Methods of Ethics), Gabriele Taylor ("Love"), Laurence Thomas ("Reasons for Loving"), Harry Frankfurt ("Some Thoughts"), Robert Nozick (The Examined Life), and John Rawls ( $A$ Theory of Justice).
} 
Epistemic Norms, the False Belief Requirement, and Love

rationality back to the drawing board. We need, more specifically, to come up with an account of epistemic rationality that leaves room for partiality toward friends. Such an account of rationality could be plausibly consistent with many other epistemic norms. ${ }^{59}$ Constraint response, however, fails to account for love's demand to adopt false beliefs in some circumstances. Recall that truth is an indispensable concept for analytic epistemology, as I tried to show in the first section of the paper. I have argued, however, that love sometimes requires that we hold false beliefs. Coming up with an account of rationality that is compatible with holding false beliefs strikes me as a losing battle: an account of rationality that does away with truth is too strong of a constraint. There are some central epistemic norms that any plausible account of rationality must respect-one of which is true belief.

Moreover, I do not think that the incommensurate response is helpful either. Recall that this response says that the value of rationality and the values of friendship and love are neither lesser than, greater than, nor equal to one another; they are just different. We, consequently, have no reason to prefer one to the other, given that they do not stand in any hierarchic relation to one another. I do not think these values are incommensurate, but even if they are incommensurate, we often treat them as though they are not mutually exclusive. It's intuitive to think that we can have both for the most part. If these values were truly incommensurate, then we would, I believe, often expect love and rationality to come apart, and not care if they did. But we do care and we do not often expect them to come apart. Perhaps this offers some reason to think love and rationality are commensurate values.

The radical response is the best explanation of the false belief requirementthere sometimes just is an unavoidable conflict between two competing values. To illuminate this conclusion, consider Tamar Gendler's observation about rationality and racism: "Living in a society structured by race appears to make it impossible to be both rational and equitable." 60 Gendler argues that rationality will often require us to form belief that are consistent with various base rates, where base rates are understood as statistical trends within a given context. Such trends, however, can be racist. For instance, suppose that the swanky DC night club, the Cosmos Club, has nearly all black employees and nearly all white club members. A person looking for an employee, where employees and club members both wear tuxedoes, would be epistemically rational to believe that some particular black person is an employee, given the base rate at the Cosmos Club. In a similar situation, a club member mistook

59 Kawall ("Friendship and Epistemic Norms") argues for a similar point. That is, he argues that epistemic partiality is not precluded for purist epistemic standards. The idea here is that purist epistemic norms can be adjusted such as to include epistemic partiality.

${ }^{60}$ Tamar Gendler, “On the Epistemic Cost of Implicit Bias," Philosophical Studies 156 (2011): 57. 


\section{J. Spencer Atkins}

black historian John Hope Franklin for an employee. Franklin writes that he felt wronged by the club member. The club member's belief, however, is formed in accordance with the evidence and, by many epistemic standards, quite rational. It is also racist. Gendler concludes that there is irreconcilable conflict between epistemic rationality and moral norms, specifically not holding racist beliefs. In a similar vein as Gendler, I have said that there is a conflict between epistemic rationality and the norms of love. Epistemic rationality would require us to be bad lovers in some circumstances. Believing truly makes for bad love. The sad conclusion is that sometimes we are forced to choose between being rational or being good lovers; we cannot always have both.

Consider a belief objection. Perhaps the beliefs we form in loving relationships involve non-propositional knowledge, knowledge by acquaintance. It might be that loving for the right reasons is, for instance, a kind of non-propositional activity. The reasons I love my partner are not true and false propositions, rather they are experiences and sensations, e.g., the experience of my lover's perfume or the way she looks when she gets mad. Bertrand Russell ${ }^{61}$ argues that knowledge by acquaintance does not involve inference, judgement, or thought. This kind of knowledge is not subject to bivalence, as propositional knowledge is. Knowledgeas defined by many analyses of knowledge-however deals with propositional knowledge; the domain of modern analytic epistemology overwhelmingly deals propositional knowledge- knowledge that - not knowledge by acquaintance. ${ }^{62}$ If this is the case, then it seems that modern analyses of knowledge will sidestep the problems I have laid out here because knowledge of one's lover is non-propositional and, consequently, outside of the scope of the epistemology I have critiqued.

In response, loving relationships likely have some elements of knowledge by acquaintance. I may enjoy-beyond the mere fact that my lover wears perfumethe experience of the smell of my lover's perfume. But this does not mean that every reason that we love our lover is non-propositional. Loving for the right reasons is often propositional because we can, as I argued, believe various false propositions about the lover, e.g., that he is a "nihilistic desperado." Thus, this objection does not capture all of the logical space. There are some instances where we must assume false propositions (that go beyond mere knowledge by acquaintance) to love our lover for the right reasons.

\footnotetext{
${ }^{61}$ Bertrand Russell, The Problems of Philosophy (London: Williams and Norgate, 1912).

${ }^{62}$ Ichikawa and Steup, "The Analysis of Knowledge."
} 


\section{Conclusion}

Love sometimes poses the false belief requirement. Love sometimes requires bad epistemic agency. Specifically, I argued that the epistemic norm of believing truly sometimes stands opposed to both the demand to love for the right reasons and the demand to avoid doxastic wronging. Stroud's constraint response-that the epistemic norms must subordinate themselves to the norms of the good life-goes too far. Epistemology cannot give up the truth condition. I proposed that this conflict is best explained by the radical response: that we must sometimes be irrational if we are to love another person. Prioritizing epistemic rationality over the demands of our lover means forsaking the demands of love. Forsaking such demands, I think, inhibits the good life. If epistemic demands inhibit the demands of love-and consequently the good life-then so much the worse for epistemic demands. 